\title{
Postharvest Enhancement of Fruits and Vegetables for Improved Human Health
}

\author{
Ron Buescher, Luke Howard, and Pat Dexter \\ Department of Food Science, University of Arkansas, 272 Young Avenue, Fayetteville, AR 72704
}

Fruits and vegetables provide substantial amounts of nutrients important for human health. They are particularly important sources of micronutrients, such as provitamins $\mathrm{A}, \mathrm{B}_{6}, \mathrm{C}$, and $\mathrm{E}$ and folacin, iron, and magnesium (Adams, 1975; Recheigl, 1982; Salunkhe, 1974; U.S. Dept. of Agriculture, 1995). Low intakes of these nutrients have been reported to be of concern in the diets of some U.S. population groups (Federation of American Societies for Experimental Biology, 1995; Pao and Mickle, 1981). Results from a recent survey indicated that fewer than one-third of American adults meet dietary guidelines, which recommend consuming a minimum of two servings of fruits and three servings of vegetables per day (Federation of American Societies for Experimental Biology, 1995; Krebs-Smith et al., 1995). Therefore, increasing consumption to recommended quantities would contribute to meeting the nutrient recommendation for a number of minerals and vitamins that are of concern in the American diet.

In addition to the nutrients known to be essential for human health, fruits and vegetables contain many other phytochemicals that may be beneficial or detrimental to health, depending on the substance and its concentration. Earlier research focused on the toxic properties of phytochemicals, while more recent emphasis has been directed toward health-promoting and chronic disease-preventing properties of

Received for publication 22 Jan. 1998. Accepted for publication 1 Oct. 1998. Published with the approval of the Director of the Arkansas Agricultural Experiment Station, Fayetteville, Arkansas. The cost of publishing this paper was defrayed in part by the payment of page charges. Under postal regulations, this paper must be hereby marked advertisement solely to indicate this fact. phytochemicals (Bloch and Thomson, 1995; Caragay, 1992; Liener, 1980). Frequent consumption of vegetables and fruits, especially green and yellow vegetables and citrus fruits, is associated with decreased susceptibility to some forms of cancer, although the mechanisms for their protective effects have not been fully determined (National Research Council, 1989a). Elevated levels of certain essential micronutrients, such as $\beta$-carotene, ascorbic acid, and vitamin $\mathrm{E}$, have been included in the search for beneficial effects of phytochemicals (Greenberg and Sporn, 1996; Steinmetz and Potter, 1991). With the exception of known toxins and the essential nutrients for which recommended dietary allowances (RDAs) have been established, information regarding the safety and efficacy of other phytochemicals in fruits and vegetables is incomplete (National Research Council, 1989b). Considering that excessive amounts of any substance can adversely affect health, enhancement of any phytochemical in fruits and vegetables must be carefully evaluated. Until the health benefits of particular phytochemicals are proven, interventions to appropriately elevate levels in fruits and vegetables should solely be directed to substances known to be beneficial (Bloch and Thomson, 1995).

Improved health and human welfare can be achieved by effective strategies that improve the micronutrient status among deficient populations. Along with opportunities to enhance the micronutrient content of fruits and vegetables by genetic improvement and other production interventions (Bouis, 1996), several postharvest opportunities exist for improving micronutrient intake from fruits and vegetables. These include: 1) increasing consumption of fruits and vegetables; 2) improving bioavailability of nutrients; 3 ) increasing levels of essential nutrients through fortification methods, and; 4) improving nutrient retention. 


\section{INCREASING CONSUMPTION OF FRUITS AND VEGETABLES}

Increasing the consumption of micronutrient-rich fruits and vegetables will improve micronutrient status and reduce risk of deficiencies. Based on the 1989-91 National Health and Nutrition Examination Survey (Federation of American Societies for Experimental Biology, 1995), the diets of most Americans are deficient in the major micronutrients provided by fruits and vegetables. According to the U.S. Dept. of Agriculture (1995), fruit and vegetable consumption among women declined an average of 7\% between 1977 and 1985. Fruit was consumed by only about half of the population on any given day, with less than one-third of the population consuming the recommended number of servings (Krebs-Smith et al., 1995). These estimates indicate the need for increasing fruit and vegetable consumption in the United States. Barriers that limit the consumption of fruits and vegetables need to be identified to develop appropriate strategies to increase intake through marketing and promotions. Strategies to improve the quality and nutrient content also need to be designed to include new product development and improved storage and handling practices.

\section{IMPROVING NUTRIENT BIOAVAILABILITY}

Although fruits and vegetables may contain significant quantities of micronutrients, some of these nutrients may be only partially absorbed for human nutrition. The term bioavailability is commonly used to describe the fraction of micronutrient absorption (FairweatherTait and Hurrell, 1996) The bioavailability of micronutrients varies greatly among different food sources. For example, only $1 \%$ to $3 \%$ of the iron from spinach (Spinacia olerace $\mathrm{L}$.) and legumes is absorbed (Tannenbaum, 1979). In comparison, iron absorption from meat products is usually $>10 \%$, since the iron is associated with heme. Calcium bioavailability is also low in certain horticultural foods, such as spinach (5\%), pinto beans (Phaseolus vulgaris) (17\%), and broccoli [Brassica oleracea (L.) var. Botrytis] (53\%) (Miller, 1996). Absorption of provitamin A carotenoids is low (Clydesdale et al., 1991). Information on the bioavailability of nutrients from fruits and vegetables is incomplete and more attention should be given to improving bioavailability.

Increasing the bioavailability of nutrients present in fruits and vegetables may be more effective than increasing nutrient levels. Bioavailability of nutrients is affected by several complex factors that may either reduce or enhance bioavailability; these factors are not fully understood. Oxalic acid, phytic acid, and tannins are known to reduce bioavailability of certain minerals, such as calcium, iron, and zinc (Miller, 1996; Zhou and Erdman, 1995). Methods to reduce the levels of these phytochemicals should enhance bioavailability of the nutrients they affect. For example, naturally occurring phytases are effective in hydrolyzing phytic acid during certain stages of processing (Reddy et al., 1982). Implementing procedures to maximize the destruction of phytic acid should reduce their interference with nutrient bioavailability.

Another approach is to increase the contents of substances that enhance bioavailability of micronutrients. For example, the bioavailability of iron is increased by reducing the level of ascorbic acid (AA), or by chelation agents such as ethylenediamine tetraacetic acid (Clydesdale, 1988; Hallberg, 1982). Therefore, interventions that improve the conservation of RAA or that involve fortification with RAA should also improve the bioavailability of iron (International Nutritional Anemia Consultative Group, 1993).

\section{NUTRIENT FORTIFICATION}

Fortification with specific nutrients could be a rapid and relative simple method for enhancing the micronutrient content of fresh and processed fruit and vegetable products to improve human health (Bauernfiend and LaChance, 1991). Nutrients are commonly added to cereal and dairy products, juices, and beverages. In some cases, nutrients are added to replace those lost during processing. Nutrients are also added to improve other characteristics of food quality, such as color, flavor, and texture. For example, AA is added to foods to retard browning reactions and improve shelf-life, and $\beta$-carotene is used for its antioxidant and color properties (Friedman, 1996; Giese, 1996). Also, calcium is a common additive used to improve fruit and vegetable texture.

Fortification of fruits and vegetables, especially those that are processed, could be used to compensate for nutrients lost during commercial processing and home preparation (Bauernfiend and LaChance, 1991). Fortification can provide levels of nutrients equivalent to those in freshly harvested fruits and vegetables, and could reduce variability in nutrient content, leading to more standardized amounts in food products. Also, fruit and vegetable products such as juices targeted for specific consumers, e.g., school children or the elderly, may be fortified with nutrients to assist in meeting their particular nutrient requirements. Another advantage of fortification is that adding the essential nutrients that may be lacking in the diet is technically feasible.

\section{ENHANCING NUTRIENT RETENTION}

Concentrations of nutrients in fruits and vegetables tend to decline during postharvest handling, storage, processing, and consumer preparation (Lund, 1988; Salunkhe, 1974; Tannenbaum, 1979). The reduction in nutrient content represents "hidden losses" of food value and quality. As much as $100 \%$ of a nutrient may be lost between the time of harvesting and consumption without detectable changes in other quality characteristics, such as color, flavor, and texture.

Losses of minerals and vitamins in fruits and vegetables vary by nutrient, type of fruit and vegetable, physical damage, type and time of processing, temperature. and storage environment (Shewfelt, 1990). These factors influence the major causes of nutrient losses, which involve disposal of tissues, leaching, and chemical alterations of particular nutrients. Although nutrients in frozen, pasteurized, and sterilized products are relatively stable, large losses may occur before processing and during preparation for consumption (Fennema, 1988; Karel, 1979; Lund, 1979; Wolf, 1983).

Peeling, trimming, and leaching. Nutrients such as vitamin $\mathrm{C}$ are concentrated in the outer leaves and peels of fruit and vegetable tissues (Mozafar, 1994). Therefore, peeling and trimming before eating fresh produce, or before cooking and processing, often result in large losses in nutrient value. The losses of nutrients (\%) caused by peeling and trimming are usually much greater than loss in weight (\%). Typically, apple (Malus $\times$ domestica Borkh.) peels contain 2-5 times more ascorbic acid than does apple flesh. On the other hand, pesticide residues also are usually more concentrated in outer tissues, occasionally preventing their safe use as food (Tannenbaum, 1979).

Water-soluble nutrients, such as ascorbic acid, folacin, niacin, riboflavin, thiamin, vitamin $\mathrm{B}_{6}$, and certain forms of minerals, can leach from tissues (Cain, 1967; Krehl and Winters, 1950). Processes that involve contact with water, such as hydro-cooling, water fluming, washing, blanching, brining, cooking, and canning, can reduce the nutrient content of fruit and vegetable tissues. Leaching is enhanced when tissues are physically injured, peeled, sliced and chopped, or heated in water (Selman, 1994).

Nutrient retention can be increased by minimizing peeling and by blanching and cooking prior to peeling and slicing. Also, minimizing the amount of water used for blanching and cooking substantially improves retention of the water-soluble nutrients (Krehl and Winters, 1950).

Chemical alterations. Vitamins in fruits and vegetables are primarily destroyed by oxidation catalyzed by enzymes, light, pro-oxidant metals, active oxygen species, or other chemical oxidants (Gregory, 1996). Extreme acid and alkaline environments can also cause vitamin hydrolysis. Temperature, $\mathrm{pH}$, and water activity are important factors affecting the rate of vitamin degradation.

Most studies of vitamin loss in fruits and vegetables have examined AA levels. In addition to being an essential nutrient, AA has reducing and antioxidative properties that are important in maintaining food quality (Liao and Seib, 1988). Both AA and its oxidized product, dehydroascorbic acid (DHAA), have similar vitamin C activity. However, only AA has reducing properties, which are important for 
inhibiting browning reactions. Oxidation of AA can result in the production of pro-oxidants in addition to DHAA, since hydroperoxide and free radicals may be formed (Gregory, 1996). Vitamin C activity is irreversibly destroyed when DHAA is hydrolyzed.

During storage of produce, DHAA increases at the expense of AA (Wills et al., 1984), and may be responsible for $>50 \%$ of the total vitamin $\mathrm{C}$ activity present in certain fresh-market fruits and vegetables. The oxidation of AA to DHAA in minimally processed jalapeño peppers (Capsicum annuиm L.) was reduced by modified atmosphere packaging (Howard and Hernandez-Brenes, 1998). Considering that amounts of DHAA in processed products may represent a significant portion of the total vitamin $\mathrm{C}$ content (Sweeney et al., 1959), failure to measure DHAA could result in inaccurate estimates of vitamin $\mathrm{C}$ content.

Only a few of the several carotenoids in fruits and vegetables have provitamin A activity (Gregory, 1996; Klein and Perry, 1982). To have such activity, the carotenoid must have at least one intact monoxygenated $\beta$-ionone ring and an isoprenoid side chain terminating in an alcohol, aldehyde, or carboxyl group. Trans- $\beta$-carotene has the greatest provitamin A activity of the carotenoids, providing $\approx 50 \%$ of the vitamin A activity of retinol. In comparison, $\alpha$-carotene has about half the vitamin A activity of $\beta$-carotene and lycopene has no vitamin A activity. Technological advancements have allowed for improved measurements of the various carotenoids to assess the provitamin A content in fruits and vegetables (Lessin et al., 1997; Muller, 1997).

Carotenoids are fat-soluble and their degradation is similar to the oxidative degradation of unsaturated lipids (Gregory, 1996). Although carotenoids are relatively stable when compared with vitamin $\mathrm{C}$ and other vitamins, they contain a series of conjugated double bonds that are highly susceptible to isomerization or oxidation. Stereoisomerization of the carotenoids can greatly reduce their vitamin A activity (Clydesdale et al., 1991; Gregory, 1996). For example, the isomerization of all trans $\beta$-carotene to 9 -cis, $\beta$-carotene results in a $62 \%$ loss in vitamin A activity. The conversion of all trans forms of carotenoids to cis isomers can be induced by light, acid, and heat.

Although cis isomers may be present in fresh produce, greater amounts usually occur in thermally processed products (Chandler and Schwartz, 1987; Lessin et al., 1997). Therefore, methods to reduce stereoisomerization of carotenoids in fruits and vegetables need to be developed to preserve vitamin A content.

In addition to stereoisomerization, the carotenoids are susceptible to oxidation, which is stimulated by oxygen, light, high temperature, oxidative enzymes, and pro-oxidant metals. Therefore, significant losses in vitamin A could occur in harvested fruits and vegetables. Currently, information on the amount of vitamin A activity in fruits and vegetables is inadequate since few studies have taken into account the different carotenoids, stereoisomers, and oxidized products (Clydesdale et al., 1991).

Chemical changes can also occur in minerals that affect their nutritional characteristics. Minerals, such as iron and calcium in fruits and vegetables, may be chemically altered and interact with other substances that affect their physiochemical properties (Miller, 1996). Changes that affect mineral solubility are particularly important, since solubility influences nutrient adsorption and also losses caused by leaching. Changes in mineral solubility are probably minor in fresh fruits and vegetables. However, processing can cause changes in the oxidation state of certain minerals, such as iron and copper. Oxidation reduces the solubility and bioavailability of mineral micronutrients (Clydesdale, 1988).

In order to reduce postharvest nutrient losses, strategies must be developed to involve all stages of commercial handling, storage, and processing as well as home and food service operations (Cain, 1967; Shewfelt, 1990; Williams, 1996). Preserving nutrients at the blanching stage will have little impact on nutrient levels if conservation practices are not also incorporated at other stages of processing and preparation for consumption (Selman, 1994). Postharvest handling and storage operations that maintain quality characteristics of color, flavor, texture, and freedom from physical and microbial damage also reduce micronutrient losses (Clydesdale et al., 1991). Although rates of nutrient degradation can be expected to be minimal in produce stored under optimum conditions, large losses can occur in fruits and vegetables stored for a long time. In contrast with losses of nutrients in fresh produce during commercial handling and storage, much greater losses generally occur during processing and during home or food service preparation of fresh or processed products for consumption (Williams, 1996).

In summary, many attractive postharvest opportunities exist for enhancing the quantity and quality of essential nutrients present in fruits and vegetables. Strategies to increase overall consumption of fruits and vegetables, improve nutrient bioavailability, increase essential nutrient content through fortification, and reduce nutrient losses are potential postharvest interventions that will promote health by improving the nutrient content and quality of the diet.

\section{Literature Cited}

Adams, C. 1975. Nutritive value of American foods. Agr. Hdbk. No. 456. U.S. Dept. Agr., Washington, D.C.

Bauernfiend, J. and P. LaChance. 1991. Nutrient additions to foods. Food and Nutrition Press, Trumbull, Conn.

Bloch, A. and C. Thomson. 1995. Position of the American Dietetic Association: Phytochemicals and functional foods. J. Amer. Diet. Assn. 95:493496.

Bouis, H. 1996. Enrichment of food staples through plant breeding: A new strategy for fighting micronutrient malnutrition. Nutr. Rev. 54:131-137.

Cain, R. 1967. Water-soluble vitamins: Changes during processing and storage of fruit and vegetables. Food Technol. 21:60-69.

Caragay, A. 1992. Cancer preventative foods and ingredients. Food Technol. 46:65-68.

Chandler, L. and S. Schwartz. 1987. HPLC separation of cis-trans carotene isomers in fresh and processed fruits and vegetables. J. Food Sci. 52:669672.

Clydesdale, F.M. 1988. Minerals: Their chemistry and fate in food, p. 57-64. In: K. Smith (ed.). Trace minerals in food. Marcel Dekker, New York.

Clydesdale, F.M., C. Ho, C. Lee, N. Monday, and R. Shewfelt. 1991. The effects of postharvest treatment and chemical interactions on the bioavailability of ascorbic acid, thiamin, vitamin A, carotenoids and minerals. Crit. Rev. Food Sci. Nutr. 30:599-638.

Fairweather-Tait, S. and R.F. Hurrell. 1996. Bioavailability of minerals and trace elements. Nutr. Res. Rev. 9:295-324.

Federation of American Societies for Experimental Biology. 1995. Third report on nutrition monitoring in the United States. Fed. Amer. Soc. for Expt. Biol. Life Sci. Res. Office. U.S. Govt. Printing Office, Washington, D.C.

Fennema, O. 1988. Effects of freeze preservation on nutrients, p. 269-317. In: E. Karmas and R. Harris (eds.). Nutritional evaluation of food processing, 3rd ed. Van Nostrand Reinhold, New York.

Friedman, M. 1996. Food browning and its prevention: An overview. J. Agr. Food Chem. 44:631-653.

Giese, J. 1996. Antioxidants: Tools for preventing lipid oxidation. Food Technol. 50:73-81.

Greenberg, E. and M. Sporn. 1996. Antioxidant vitamins, cancer and cardiovascular disease. N. Engl. J. Med. 334:11189-11190.

Gregory, J. 1996. Vitamins, p. 531-616. In: O. Fennema (ed.). Food chemistry. Marcel Dekker, New York.

Hallberg, L. 1982. Effect of vitamin C on the bioavailability of iron from food, p. 49-64. In: J. Counsell and D. Hornig (eds.). Vitamin C-ascorbic acid. Applied Science, London.

Howard, L.R. and C. Hernandez-Brenes. 1998. Antioxidant content and market quality of jalapeño pepper rings as affected by minimal processing and modified atmosphere packaging. J. Food Qual. 21:317-327.

International Nutritional Anemia Consultative Group. 1993. Iron EDTA for food fortification. Intl. Nutr. Anemia Consultative Group, Washington, D.C.

Karel, M. 1979. Effect of storage on nutrient retention of foods. Food Technol. 33:36-37.

Klein, B. and A. Perry. 1982. Ascorbic acid and vitamin A activity in selected vegetables from different geographical areas of the U.S. J. Food Sci. 47:941-945.

Krebs-Smith, S., D. Cook, A. Subar, L. Cleveland, and J. Friday. 1995. U.S. adult's fruit and vegetable intakes. 1989 to 1991; a revised baseline for the healthy people 2000 objective. Amer. J. Pub. Health 85:1623-1629.

Krehl, W. and R. Winters. 1950. Effect of cooking methods on retention of vitamins and minerals in vegetables. J. Amer. Diet. Assn. 26:966-972.

Lessin, W., G. Catigani, and S. Schwartz. 1997. Quantification of cis-trans isomers of provitamin A carotenoids in fresh and processed fruits and vegetables. J. Agr. Food Chem. 45:3728-3732.

Liao, M. and P. Seib. 1988. Chemistry of 1-ascorbic acid related to foods. Food 


\section{Colloquium}

Chem. 30:289-312.

Liener, I. 1980. Toxic constituents of plant foodstuffs. Academic, New York Lund, D. 1979. Effect of commercial processing on nutrients. Food Technol. 33:28-34.

Lund, D. 1988. Effects of heat processing on nutrients, p. 319-354. In: E. Karmas and R. Harris (eds.). Nutritional evaluation of food processing. 3rd ed. Van Nostrand Reinhold, New York.

Miller, D. 1996. Minerals, p. 617-649. In: O. Fennema (ed.). Food chemistry. Marcel Dekker, New York.

Mozafar, A. 1994. Plant vitamins: Agronomic, physiological and nutritional aspects. CRC Press, Boca Raton, Fla.

Muller, H. 1997. Determination of the carotenoid content in selected vegetables and fruit by HPLC and photodiode array detection. Z. Lebensm. Unters Forsch. 204:88-94.

National Research Council. 1989a. Diet and health: Implications for reducing chronic disease risk. Natl. Acad. Press, Washington, D.C.

National Research Council. 1989b. Recommended dietary allowances. Natl. Acad. Press, Washington, D.C.

Pao, E. and S. Mickle. 1981. Problem nutrients in the United States. Food Technol. 35:58-79.

Recheigl, M. 1982. Handbook of nutritive value of processed food. Vol. I. Food for human use. CRC Press, Boca Raton, Fla.

Reddy, N., S. Sathe, and D. Salunkhe. 1982. Phytates in legumes and cereals. Adv. Food Res. 28:1-92.
Salunkhe, D.K. 1974. Storage, processing and nutritional quality of fruits and vegetables. CRC Press, Cleveland, Ohio.

Selman. 1994. Vitamin retention during blanching of vegetables. Food Chem. 49:137-147.

Shewfelt, R. 1990. Sources of variation in the nutrient content of agricultural commodities from the farm to the consumer. J. Food Qual. 13:37-54.

Steinmetz, K. and J. Potter. 1991. A review of vegetables, fruit and cancer. Cancer Causes and Control 2:325-357, 427-442.

Sweeney, J., G. Gilpin, M. Staley, and M. Martin. 1959. Effect of cooking method on broccoli. J. Amer. Diet. Assn. 35:354-358.

Tannenbaum, S. 1979. Nutritional and safety aspects of food processing. Marcel Dekker, New York.

U.S. Dept. of Agriculture. 1995. Nationwide food consumption survey; continuing survey of food intakes by individuals. NFCS, CSF11 Rpt. No. 854.

Williams, P. 1996. Vitamin retention in cook/chill and cook/hot-hold hospital food services. J. Amer. Diet. Assn. 96:490-498.

Wills, R., P. Wimalasiri, and H. Greenfield. 1984. Dehydroascorbic acid levels in fresh fruit and vegetables in relation to total vitamin C activity. J. Agr. Food Chem. 32:836-838.

Wolf, I. 1983. Handbook of processing and utilization in agriculture. CRC Press, Boca Raton, Fla.

Zhou, J. and J. Erdman. 1995. Phytic acid in health and disease. Crit. Rev. Food Sci. Nutr. 35:495-508. 